\title{
REPORTS ON BLINDNESS IN GLASGOW (JOINT COMMITTEE FOR THE SOUTH- WEST OF SCOTLAND FOR THE ADMINISTRATION OF THE BLIND PERSONS ACT, I920), 1926
}

By Dr. A. FREELAND FERGUS and Dr. JAMES L. HALLIDAY, with an Introduction by Dr. A. S. M. MAcGREGOR, M.O.H., Glasgow.

THE report is concerned with the examination of 1,206 adult blind persons out of a total figure of $\mathrm{I}, 587$ persons over sixteen years of age on the register of the blind in Glasgow. In a third of the cases the primary cause of blindness could not be ascertained, but in half of these there were grounds for suggesting a possible cause.

In at least I7 per cent., and probably in many more, the disability was due to venereal disease.

In 4.8 per cent. blindness was referable to gonococcal infection, and in all of these it is to be inferred from the report that infection occurred at birth. In this connection a graph is published showing the incidence of gonococcal. ophthalmia neonatorum in Glasgow during the years I9I2-I924, which affords further evidence, if such were needed, of the inestimable value of the prophylactic use of nitrate of silver at birth.

Statistics are given in tabular form showing the incidence of impairment of vision in the cases of bacteriologically demonstrated gonococcal ophthalmia neonatorum, and in a prefatorial comment it is pointed out that out of a total of I74 cases of such impairment of vision occurring during the years I9I4-I924 only eighteen occurred during the last three years; and it is suggested that here is a demonstration of greatly improved results in which prompt institutional treatment, such as has been established at the Baird Street Reception House, may very probably be an important factor. An analysis of the figures concerned shows, however, that, while the percentage of cases of impaired vision in the total $I, 544$ 


\section{BRITISH JOURNAL OF VENEREAL DISEASES}

cases concerned during the whole eleven years is II per cent. (I74 cases), the percentage for the last three years is not less than 8.7 (I8 out of 206 cases), a figure which gives no ground for complacency. In this matter it would, however, be unwise to place much reliance on statistics which are necessarily open to criticism, while there can be no doubt as to the great value of early institutional treatment.

Acquired syphilis was found to be responsible for $6 \cdot 8$, possibly $7 \cdot 6$, congenital syphilis for $5 \cdot 8$, possibly $7 \cdot 8$, per cent. of cases of blindness.

It is estimated that at least 30 per cent. of cases treated at venereal disease centres for syphilis relinquish their treatment before a cure has been effected. The importance of this point is emphasised in view of the liability of such persons either themselves to develop subsequently eye affections, or to transmit them to their offspring, and it is suggested that herein is an argument for some form of notification.

A. C. H. 